\title{
'Universal' immunizations get a boost in India
}

The economic liberalization that began in India two decades ago might have produced an unwanted side effect-the production of vaccines against illnesses such as measles and tetanus seems to be threatened by the disappearance of more than a dozen government-owned vaccine producers. Now, in response partly to calls made by some parliament members, the Indian health ministry might move to reverse its shift toward leaning on the private sector and pay greater attention to these public sector producers (in which the government owns a majority stake) when it comes to vaccine production.

A 7.6 billion rupee ( $\$ 170$ million) revival package was, as Nature Medicine went to press, still awaiting a cabinet nod to perk up the almost 50-year-old, government-owned Indian Drugs and Pharmaceuticals Limited (IDPL), the largest vaccine producer of its kind. "We are on a path to recovery, and I am confident IDPL will very soon come out of the stigma of being sick," says its managing director Jayashree Gupta.

Perhaps more notably, in early March the country's health ministry ordered the revival of three public sector vaccine producers, reversing its January 2008 decision to close them down.

More than a dozen public sector vaccine producers were closed down in the last decade, says Yennapu Madhavi of the National Institute of Science, Technology and Development Studies in New Delhi. Until their closure in 2008 , the three producers supplied $70-80 \%$ of the six primary vaccines required to vaccinate the 25 million babies born each year under the universal immunization program (UIP), she told Nature Medicine. (These vaccines cover diphtheria, pertussis, tetanus, poliomyelitis, childhood tuberculosis and measles.)

Although the number of private companies producing vaccines has increased in India in recent years, they have focused on new and combination vaccines, Madhavi says. Combination vaccines-which combine expensive vaccines, such as that for hepatitis $\mathrm{B}$, with at least one UIP vaccine, such as the measles jab — are basically the industry's ploy to capture markets for their new vaccines through the back door, says Madhavi.

Kanikaram Satyanarayana, deputy director general of the Indian Council of Medical
Research, which is under the health ministry, says a draft vaccine policy that calls for urgent revival and modernization of all of the government-owned vaccine producers is under consideration.

Madhavi says that private sector producers that wish to produce new or combination vaccines might be obliged to produce some UIP vaccines (individually and not in combination vaccines) to fill any shortfalls in government production.

The policy is not in place yet, but the private sector does not see any problem. "We do supply UIP vaccines on demand," says V.K. Vinayak, head of research at Panacea Biotec in New Delhi. "Revival of pubic sector units is welcome news, and there is space for everyone in the Indian vaccine market."

Varaprasad Reddy, managing director of Shantha Biotech in Hyderabad, which is 94\% owned by Sanofi-Aventis, agrees. He says the revival of government-run vaccine producers is "a great relief, as we will have no obligation to supply the primary UIP vaccines to the government."

Killugudi Jayaraman, Bangalore, India

\section{Science seen as olive branch to the Muslim world}

In an effort to bolster scientific partnerships in the Middle East, two US congressmen have introduced a bill that would fund research and education in Muslim-majority countries. The move follows a speech made last summer by President Barack Obama at Cairo University in Egypt in which he promised to ramp up science diplomacy in the Arab world.

"We need to keep America in the business of exporting one of our greatest national resources-our intellectual and creative capacity through science," California Democrat Howard Berman told Nature Medicine.

The Global Science Program for Security, Competitiveness and Diplomacy Act, co-sponsored in March by Berman and Jeff Fortenberry, a Republican from Nebraska, would provide grants of up to five years to universities and businesses and fund infrastructure for research in a number of specific fields, including multi-drug-resistant and water-borne diseases, renewable energy and nuclear nonproliferation, among others. Research into sensitive subjects such as bioterrorism and select agents would not be funded. The bill, which does not specify a budget, also aims to create a 'global virtual science library' that would make scientific journals available at little to no cost.

Ahmed Zewail, an Egyptian-born chemist at the California Institute of Technology and a member on the President's Council of Advisors on Science and Technology, applauds the legislation. "This is about creating the infrastructure, exchanges and management" in science between the US and the Muslim world,

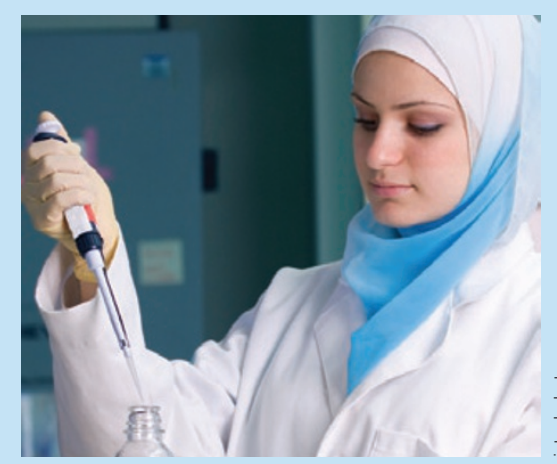

Hands-on diplomacy: Bridging Middle East science. says Zewail, who was one of three science envoys appointed by Secretary of State Hillary Clinton in November.

Still, he concedes that some countries in the region do not have the capacity to support research, even if paid for by US taxpayers. "Some countries are at different levels," he says. "Some will only be able to contribute human resources," but others should produce concrete results.

Many scientists are hailing the move, although most do not expect to see groundbreaking findings come out of the program. Nicholas Vonortas, director of the Center for International Science and Technology Policy at George Washington University in Washington, DC, sees the legislation as an effort primarily to "project an image that we're not just destructive, but constructive."

To become law, the bill must first pass through both the House Foreign Affairs Committee and the Committee on Science and Technology, before going before the entire chamber. Neither has scheduled a hearing for the program.

Peter Granitz, Washington, DC 